\title{
Abordagens sobre sustentabilidade no ensino CTS: educando para a consideração do amanhã
}

\section{Approach to sustainability in CTS teaching: educating for the consideration of tomorrow}

\author{
Nadia Magalhães da Silva Freitas* \\ Carlos Alberto Marques**
}

\begin{abstract}
RESUMO
Estamos vivenciando processos insustentáveis de desenvolvimento, cujo passivo principal materializa-se no crescimento da pobreza e na crise ambiental. O campo educacional não está alheio a essas questões, especialmente aos aspectos socioambientais. É nesse contexto que destacamos a importância de um ensino que problematize as relações entre Ciência, Tecnologia e Sociedade (CTS), cuja perspectiva e papel expressam as diversas ordens de implicações no campo social, econômico, ambiental, ético, entre outras. O presente trabalho, de natureza qualitativa, é parte de uma pesquisa mais ampla e foi conduzido buscando responder ao seguinte problema: em que termos se observa a inserção do tema (in)sustentabilidade em trabalhos de tese e de dissertações que se caracterizam como análise de práticas/ações de educação com enfoque CTS, na abordagem de temas socioambientais, nas pesquisas da área de ensino, no contexto da Educação em Ciências/ Educação Científica e Tecnológica? Os resultados revelam que cerca de 1/4 desses trabalhos sequer referenciam os termos conceitos sustentabilidade e sustentável. Dos mais de 70\% dos trabalhos que fizeram notações, em pouco mais da metade deles constava mera menção aos referidos termos. A sustentabilidade constitui-se de um novo valor, do pensar no amanhã e do
\end{abstract}

DOI: $10.1590 / 0104-4060.49478$

* Universidade Federal do Pará. Belém, Pará, Brasil. Avenida Augusto Corrêa, n. 1. Campus Universitário do Guamá. Setor Básico. Guamá. CEP: 66075-110.E-mail: nadiamfs@yahoo.com.br

** Universidade Federal de Santa Catarina. Centro de Ciências da Educação. Florianópolis, Santa Catarina, Brasil. Campus Reitor João David Ferreira Lima, s/n - Trindade. CEP: 88040-970. E-mail: bebetomarques07@gmail.com 
agir no presente, o que demanda que ela seja infundida e problematizada em todos os contextos societários, inclusive na educação.

Palavras-chave: Educação em Ciências. CTS. Sustentabilidade.

\begin{abstract}
We are experiencing unsustainable development processes, whose main outcomes materialize; in the growth of poverty and the environmental crisis. The educational field is not strange to the socio-environmental issues, especially when it comes to socio-environmental aspects. In this context, we highlight the importance of a teaching process that problematizes the relations between Science, Technology and Society (STS), which express implications of several orders: namely social, economic, environmental, and ethical, among others. The present qualitative study is part of a broader research. In this context, we aim to answer the following problem: in what terms is observed the insertion of the theme (in) sustainability, in thesis and dissertations, that represents analyzes of practices/actions with STS focus and socio-environmental themes, in the context of Education in Science/Scientific and Technological Education? The results show that about $1 / 4$ of these studies have not even referenced the terms sustainability and sustainable. Among the seventy percent of the works that referred to these concepts, little more than half of them included merely mentions to the words. Sustainability can be considered new standard, of thinking about tomorrow and of acting in the present, which demands that it be infused and problematized in all societal contexts, including education.
\end{abstract}

Keywords: Science Education. STS. Sustainability.

\title{
Introdução
}

Do último século aos tempos atuais, inúmeros eventos têm marcado acentuadamente uma crise ambiental de dimensão e efeitos muito preocupantes. Tais eventos, inter-relacionados, dizem respeito, por exemplo: ao aumento da produção de resíduos sólidos e de contaminantes industriais, ao desmatamento, à degradação e à desertificação dos solos, ao acelerado aumento da concentração de gases de efeito estufa na atmosfera, à perda crescente da diversidade biológica, entre outros aspectos (MARQUES, 2015). Esse estado de coisas está relacionado ou deriva do que chamamos de "desenvolvimento", o qual tem trazido passivos não somente para o campo ambiental, mas também se 
desdobra em efeitos deletérios para o campo social (PORTO-GONÇALVES, 2012; VILCHES; GIL-PÉREZ, 2015).

Assim a sustentabilidade configura-se como questão central nos tempos atuais e, por isso, tem sido foco de muitas discussões e debates em diferentes campos de estudo (LEFF, 2016; MARQUES, 2015; NASCIMENTO, 2012a; NINIS; BILIBIO, 2012). O campo educacional não está alheio ao contexto de crise ambiental. Nesse sentido, vários trabalhos têm buscado difundir o pressuposto da sustentabilidade, tanto em âmbito nacional como internacional, na perspectiva de construção de um futuro previsível para a humanidade (GUERRA; FIGUEIREDO, 2014; LAURIE et al., 2016).

Ainda no campo educacional, destacamos a tendência do ensino que problematiza as relações entre Ciência, Tecnologia e Sociedade (CTS). Trata-se de uma perspectiva de ensino (enfoque CTS) que reconhece que o "[...] desenvolvimento da ciência e da tecnologia tem acarretado diversas transformações na sociedade contemporânea [...]" (PINHEIRO; SILVEIRA; BAZZO, 2009, p. 72); e que as interações CTS expressam implicações de diversas ordens, a saber: social, econômica, ambiental, éticas, entre outras (BAZZO, 2014).

As discussões sobre (in)sustentabilidade, em interlocução com questões afeitas às relações CTS, mostram-se pertinentes e oportunas, precisamente ao considerarmos os seguintes argumentos:

[...] 1) o momento socioambiental atual é tenso, quando se considera os limites do planeta; 2) a tecnologia, produto do conhecimento científico, parece não ter sido construída em vinculação a uma ética que indique o sentido e os limites de sua difusão e aplicação no meio social; 3) a educação científica passou por um período de "cegueira" em relação às consequências que o uso do conhecimento científico poderia ocasionar à sociedade, em virtude do obscurantismo técnico, fomentado pelo cartesianismo. (VASCONCELOS; FREITAS, 2012, p. 91).

Assumindo-se que, em maior ou menor intensidade, diferentes resultantes das relações CTS estão implicados no quadro de eventos associados a (in)sustentabilidade - o que anuncia convergências destes dois campos (Sustentabilidade e CTS) -, o presente trabalho foi conduzido para responder ao seguinte problema de pesquisa: em que termos se observa a inserção do tema (in)sustentabilidade, em trabalhos de tese e de dissertações que se caracterizam como análise de práticas/ações de educação com enfoque CTS, na abordagem de temas socioambientais, nas pesquisas da área de ensino, no contexto da Educação em Ciências/Educação Científica e Tecnológica? 


\section{Considerações iniciais}

Parte da pesquisa aqui relatada fundamenta-se na abordagem qualitativa, correspondendo a um processo descritivo e analítico (OLIVEIRA, 2014). O procedimento metodológico de coleta de dados referiu-se ao desk research ${ }^{1}$, tendo como fonte de dados o Banco Digital de Teses e Dissertações (BDTD), do Instituto Brasileiro de Informação em Ciências e Tecnologias (IBICT). Em um primeiro plano, selecionamos teses e dissertações (T\&D), correspondendo ao período de 2005 a 2015; a partir do macro descritor CTS, constituiu um total de 247 trabalhos. Posteriormente, selecionamos aqueles trabalhos vinculados ao campo educacional (127 registros), para em seguida proceder a mais uma seleção, qual seja: trabalhos cuja configuração de pesquisa apresentava-se como de pesquisa-ação $o^{2}$, o que representou 50 trabalhos (05 teses/45 dissertações).

Dessa segunda amostra de trabalhos, elegemos aqueles que tratavam questões socioambientais, totalizando 35 textos (04 teses/31 dissertações), os quais foram submetidos à busca dos seguintes descritores/termos: sustentabilidade $\mathrm{e}$ insustentabilidade; sustentável, sustentáveis, insustentável e insustentáveis. Desses 35 trabalhos, oito não apresentavam tais descritores ( 08 dissertações - 23\%) e 27 ( 04 teses/23 dissertações - 77\%) registraram um ou mais desses descritores.

Do conjunto de 27 trabalhos, maiores notações foram observadas para os descritores sustentabilidade (145 registros - 44,6\%) e sustentável (140 registros $-43 \%$ ), em ambos os casos, incluídos aqui também os seus derivativos. Na continuidade, buscamos identificar a natureza da presença desses descritores nos seguintes termos: mencionado, descrito ou discutido. Destacamos aqui a distribuição percentual, segundo tais categorias: sustentabilidade (mencionado - 79 registros $/ 54,5 \%$; descrito - 44 registros $/ 30,3 \%$; discutido - 22 registros $/ 15,2 \%$ ) e sustentável (mencionado - 88 registros $/ 62,9 \%$; descrito - 37 registros $/ 26,4 \%$; discutido -15 registros $/ 10,7 \%$ ). Nota-se, portanto, uma superioridade da menção dos termos.

No processo analítico, sob a perspectiva interpretativa (ESTEBAN, 2010) e para fins deste artigo, apresentamos os resultados das análises de dois conjuntos de T\&D: o primeiro refere-se àqueles trabalhos que não se observou a presença dos descritores elencados, o outro, formado por aqueles que fizeram menção aos descritores. Isso foi feito para destacar a possibilidade e a necessidade de

1 Pesquisa de dados secundários.

2 Ao considerarmos trabalhos com essa configuração de pesquisa, pensamos que esses, na realidade, representam experiências pedagógicas que procuravam, de algum modo, a partir dos seus resultados, transformar o cenário educacional, no sentido de contribuir para qualificação do ensino. 
aprofundamento das questões da (in)sustentabilidade, incidentes nas relações CTS. Aspectos, esses, que permitem anunciar, segundo nossa tese, convergências entre o pressuposto da sustentabilidade e abordagens educacionais com enfoque CTS na educação em ciências/educação científica e tecnológica.

\section{Dois conceitos concorrentes: desenvolvimento sustentável e sustentabilidade}

No léxico global, os termos sustentabilidade e desenvolvimento sustentável são utilizados de forma unívoca, ainda que consideremos possuírem semânticas diferenciadas. Isso posto, iniciamos com uma breve abordagem exemplificativa sobre as origens e as compreensões desses dois termos, primeiro sobre desenvolvimento sustentável e, posteriormente, sobre sustentabilidade. Fazemos isso para cotejar desdobramentos de entendimentos e aplicação no campo educacional.

As obras The Loves of Plants and Animals: Romantic Science and the Pleasures of Nature (DARWIN, 1794) e Temple of Nature; or, Origin of Society (DARWIN, 1804) apresentam os fundamentos basilares das discussões ambientais. Isso porque reconhece a natureza como um valor supremo a ser resguardado, esquivando-se de uma compreensão utilitarista da natureza, ou seja, mero recurso a ser explorado. Seguiu-se a obra Waden (THOREAU, 2014), um manifesto poético que tecia críticas ao desperdício da sociedade industrial a partir do qual propôs o retorno a simplicidade.

Também vale destacar os esforços de John Muir a partir da elaboração de artigos e livros, como John Muir's Studies in the Sierra (MUIR, 1898), que narravam suas viagens e ideias naturalistas, infundindo, em diferentes tipos de leitores, inclusive políticos, a necessidade de preservação da natureza. Tal empreendimento era motivado pelas constatações da degradação ambiental, observadas em suas viagens. Fato é que suas ideias levaram a criação do Parque Nacional de Yosemite, Califórnia, Estados Unidos das Américas, em 1890. Entretanto, a partir da publicação do livro Silent Spring (Primavera Silenciosa), de Rachel Carson, em 1962, a problemática ambiental ressoa fortemente (CARSON, 2010).

A Conferência das Nações Unidas sobre o Meio Ambiente Humano (CNUMAD), realizada em Estocolmo, em 1972, e ainda a publicação do relatório The Limits to Growth (Limites do Crescimento) (MEADOWS et al., 1973) também contribuíram para colocar em evidência a necessidade de redefinir a intensidade dos usos dos recursos naturais. A perspectiva era colocar a ideia de limites, no 
sentido de que a natureza impõe limites à sociedade, notadamente, ao crescimento econômico ilimitado sob a base de recursos limitados.

A publicação do Relatório de Brundtland, com o título Our Common Future (Nosso Futuro Comum), elaborado pela Comissão Mundial sobre Meio Ambiente e Desenvolvimento da Organização das Nações Unidas, colocou, decisivamente, o conceito de Desenvolvimento Sustentável na agenda política, o qual é definido como aquele capaz de "[...] satisfazer as necessidades das gerações presentes, levando em consideração as necessidades das gerações futuras" (COMISSÃO, 1991, p. 46). Nesse documento, o conceito de Desenvolvimento Sustentável representa uma tentativa de passar a ideia de impulsionar o desenvolvimento de tecnologias, chamadas de mais limpas, e individualizar as responsabilidades sociais sobre os danos ambientais, salvaguardando os processos econômicos e industriais. Mas tudo isso não esconde sua contradição interna, semeando uma ideia de equilíbrio entre desenvolvimento/crescimento econômico e proteção ambiental. Ora, é evidente que a perspectiva de crescimento ilimitado sobre uma base de recursos (planeta Terra) limitada é inconciliável.

Apesar de haver grande apropriação do conceito de Desenvolvimento Sustentável por várias esferas da sociedade (FAUSTINO; AMADOR, 2016), isso não significa dizer que há consenso em torno dele. Há quem diga que esse conceito trate apenas de uma ideia-força, uma visão de futuro, sobre a qual a humanidade precisa fundamentar seus objetivos (VEIGA, 2005, 2008). Mas há também aqueles que se refiram a ele como uma falácia, posto que se observa a constituição de discursos que servem meramente a propósitos desenvolvimentistas e mercadológicos (CAVALCANTI, 2002, 2012).

É inegável, todavia, que o conceito de Desenvolvimento Sustentável encerra contradições e conflitos, notadamente ao "[...] preconizar um futuro comum para todos, através de uma estratégia de desenvolvimento dentro do sistema capitalista [...]" (OLIVEIRA, 2012, p. 82). Ora, a insustentabilidade generalizada de todos os campos societários é, justamente, fruto de um “[...] processo recursivo estabelecido pela lógica de funcionamento do capital juntamente com os processos e as ideologias racionalizadoras que foram se estabelecendo ao longo do processo histórico" (MELO, 2006, p. 15). Assertiva que se traduz pela face da hoje vivenciada crise ambiental (e também social), expressão do passivo constantemente produzido por esse modelo de desenvolvimento adotado.

Por sua vez, o termo sustentabilidade tem sido empregado nos mais diversos campos do saber, assumindo significados e valores distintos, o que o caracteriza como um conceito polissêmico. Por vezes, é considerado até como "[...] uma espécie de modismo e sem que exista fundamento teórico" (FAUSTINO; AMADOR, 2016, p. 2022). A noção de sustentabilidade parece ter duas raízes, decorrentes das reflexões de seu sentido no contexto da ecologia e da econo- 
mia (NASCIMENTO, 2012b; VEIGA, 2010). Assim, no âmbito da ecologia, a sustentabilidade refere-se "[...] à capacidade de recuperação e reprodução dos ecossistemas (resiliência) em face de agressões antrópicas [...] ou naturais [...]" (NASCIMENTO, 2012b, p. 51). Já na segunda, o termo sustentabilidade foi apreendido pela esfera econômica, servindo como adjetivo do desenvolvimento (Desenvolvimento Sustentável), cuja abordagem já foi anteriormente realizada, ainda que brevemente.

Embora de ampla utilização, o conceito sustentabilidade é de difícil compreensão (VEIGA, 2010). De todo modo, afiliamo-nos a definição de Boff (2012), a saber:

\begin{abstract}
Sustentabilidade é toda a ação destinada a manter as condições energéticas, físico-químicas que sustentam todos os seres, especialmente a Terra viva, a comunidade de vida e a vida humana, visando sua continuidade e ainda atender as necessidades da geração presente e das futuras, de tal forma que o capital natural seja mantido e enriquecido em sua capacidade de regeneração, reprodução e coevolução (BOFF, 2012, p. 107).
\end{abstract}

Na mesma linha de Boff (2012), compreendemos que o termo sustentabilidade deva ser visto como expressão de um conceito integrativo, complexo, uma espécie de conceito "guarda-chuva". E, na condição literal de um guarda-chuva, as varetas organizam sua estrutura e expressam suas várias dimensões (social, econômica, ambiental, entre outras), que, embora distintas, possuem relações de interdependência.

Avançando na compreensão do conceito de sustentabilidade, aportada por Boff (2012), podemos destacar os sentidos dos dois termos fortes em circulação: sustentável (adjetivo) e sustentabilidade (substantivo), a saber:

[...] como um adjetivo [sustentável] é adicionado a qualquer coisa sem mudar a natureza da coisa; por exemplo, eu posso reduzir a poluição química de uma fábrica colocando filtros em suas chaminés que liberam gases, mas a forma da empresa interagir com a natureza, de onde ela retira a matéria-prima para a produção, não muda; continua a devastar. Sua preocupação não é o ambiente, mas o lucro e a competitividade que têm que ser garantidos. Assim, a sustentabilidade é acomodação e não mudança; é um adjetivo, não substantivo. Sustentabilidade como substantivo exige uma mudança na relação com a natureza, a vida e a Terra. A primeira mudança começa com outra visão da realidade. [...]. Nós não 
estamos fora e acima dela como um dominador, mas dentro e quem se importa em alavancar seus ativos, respeitando seus limites. [...] (BOFF, 2011, p. 1, grifo nosso).

Assim, considerando que os substantivos designam qualidades (POLITO, 2004), Boff (2011), decerto, "[...] ao teorizar sobre sustentabilidade como adjetivo e substantivo, nos faz refletir que precisamos entender a sustentabilidade como substantivo, como qualidade do desenvolvimento e, nesta perspectiva, fundamental, essencial para a sociedade". (FONSECA NETO; FREITAS; FREITAS, 2017, p. 135).

\section{O tema da sustentabilidade na centralidade dos estudos sobre questões socioambientais: preocupações pertinentes, apreensões esquecidas}

As questões socioambientais constituem-se de preocupações legítimas e de crescente interesse social, pois demandam compreensões das complexas relações que se estabelecem entre ciência, tecnologia, sociedade e ambiente. Talvez, por conta disso, energia, telefone celular, combustível, dengue, polímeros, alimentos, água e radioatividade tenham sido questões tratadas nas T\&D, embora não tenham sido abordadas pela ótica da (in)sustentabilidade (23\% dos trabalhos, como referido anteriormente).

Reconhecemos que, ao se trabalhar as questões socioambientais, torna-se impossível esgotá-las no âmbito da sala de aula, tanto para fins de ensino como de pesquisa. Contudo, reconhecemos, também, que contemporaneamente há necessidade de considerarmos a emergência dos contextos de (in)sustentabilidade. Assim pensando, trazemos algumas possibilidades de abordagem à (in)sustentabilidade que inclusive refletem nossas próprias experiências em sala de aula.

No trabalho de dissertação Vivenciar para apreender: o meio ambiente como contexto para o ensino de polímeros (SILVA, 2014), observa-se que as atividades desenvolvidas permitiram aos alunos refletirem sobre os impactos da produção e do descarte inadequado do lixo (resíduos) no ambiente, aspectos que permitiriam problematizar, por exemplo, sobre "[...] os valores culturais da sociedade de consumo, do consumismo, do industrialismo, do modo de produção capitalista e dos aspectos políticos e econômicos da questão do lixo" (LAYRARGUES, 2002, p. 179). Ao assim fazê-lo, inexoravelmente, muitos aspectos seriam postos, "exigindo" referências à (in)sustentabilidade. 
Nesse trabalho, foi tratada a questão da reciclagem, que além de ser considerada uma solução pragmática para o problema do lixo, encerra aspectos perniciosos da sua própria cadeia, a exemplo da inclusão da perversa da "profissão" de catador de lixo, abrindo a possibilidade da discussão da dimensão social do lixo. Esse estado de coisas precisa ser reconhecido como um processo de insustentabilidade, constituindo "[...] a face oculta do sistema capitalista associada à produção de resíduos". (ZANETI; SÁ; ALMEIDA, 2009, p. 188).

$\mathrm{Na}$ dissertação intitulada Os três momentos pedagógicos no ensino de ciências na educação de jovens e adultos da rede pública de Goiânia, Goiás: o caso da dengue, Lyra (2013) buscou tratar a questão da dengue na perspectiva de uma aprendizagem com significado social. Como sabemos, o Aedes aegypti, vetor da dengue (e também da chikungunha e do vírus Zika, "[...] encontrou no mundo moderno condições socioambientais muito favoráveis para uma rápida expansão [...].” (PIMENTA JÚNIOR, 2015, p. 388). A questão da dengue apresenta-se como uma questão socioambiental complexa, pois está ligada ao precário saneamento ambiental e, ainda, é refém das decisões tecnocráticas e inseridas em um contexto de doenças negligenciadas ${ }^{3}$. Assim podemos afirmar, já de início, a configuração de um processo de insustentabilidade política, com sérios desdobramentos para o campo social e ambiental.

No trabalho de Cortez (2014), O legado de Madame Curie: uma abordagem CTS para o ensino de radioatividade, o assunto radioatividade foi tratado sob uma perspectiva multidisciplinar. É nessa perspectiva que poderíamos nos referir as implicações sociais do desenvolvimento do projeto Manhattan (projeto para o desenvolvimento da bomba atômica) e sua aplicação em Hiroshima e Nagasaki, como “[...] primeiro ponto de inflexão da concepção otimista do caráter benfeitor da ciência tecnologia, junto com as preocupações dos problemas ambientais". (SILVEIRA; BAZZO, 2009, p. 686).

É bem verdade que os avanços da ciência e da tecnologia trouxeram benefícios à sociedade; mas também expandiram a capacidade de destruição do homem, tanto em relação à natureza quanto ao próprio homem. É nesse sentido que podemos nos valer da proposição de "Educar para nunca mais", que busca “[...] além da promoção da história, o resgate e a reconstrução da memória [...] lembrar das violações para que elas não voltem a acontecer" (OLIVEIRA; QUEIROZ, 2015, p. 57). Parece ser esse o sentido atribuído pelo então presidente dos Estados Unidos da América, Barack Obama, em sua visita histórica a Hiroshima (2016), qual seja: a “[...] memória da manhã do dia 6 de agosto de 1945 não deve

3 Doenças endêmicas de natureza infecciosa e parasitária que acometem, geralmente, população de baixa renda, cujo investimento em pesquisa, produção de medicamentos e controle são reduzidos. 
nunca desaparecer" (AGENCIA BRASIL, 2016, p. 1). Assim corroboramos com Trigueiro (2012, p. 1) quando afirma que "Não há sustentabilidade sem paz"; de fato, sem paz a sustentabilidade é improvável e indeterminada.

\section{Sustentabilidade e sustentável: de fato, mantras da atualidade?}

Considerando os percentuais relativos à mera menção aos termos sustentabilidade (79 registros/54,5\%) e sustentável (88 registros/62,9\%), podemos afirmar que o uso dos termos sustentabilidade e, também, de desenvolvimento sustentável, apoiados em Cavalcanti (2012, p. 35-36), “[...] dá a impressão de se ter convertido numa espécie de mantra da atualidade. É repetida quase à exaustão em todo tipo de discurso relacionado com desenvolvimento (e crescimento) econômico". De fato, "[...] passou a servir a gregos e troianos quando querem exprimir vagas ambições de continuidade ou perenidade. Todas remetendo ao futuro" (VEIGA, 2010, p. 12). Trata-se, portanto, de simples termo da linguagem, mero nominalismo, e, assim, "[...] não passam de nomes, de simples emissões de voz. O conceito não é a coisa, é palavra (VACARRO, 2013, p. 145), e “[...] as palavras não podem oferecer transcrições literais, mas meras referências metafóricas" (REST, 2009, p. 149).

A menção ao termo sustentabilidade está frequentemente associada à dimensão ambiental, geralmente, em detrimento das demais dimensões. Reconhecemos que as questões ambientais, atualmente, estão no centro das discussões relativas à (in)sustentabilidade. E, chamar a atenção para a questão da sustentabilidade ambiental ou, mais precisamente, para a insustentabilidade ambiental, deveria pressupor ponderar sobre o "[...] impacto ambiental irrecorrível do crescimento econômico sobre os recursos e os sumidouros da natureza" (CAVALCANTI, 2012, p. 35). Ainda mais se considerarmos que, sob a ótica da Termodinâmica, especificamente da Lei da Entropia (Segunda Lei da Termodinâmica), todo processo econômico é entrópico (CECHIN, 2010).

Ao tratar do tema da sustentabilidade ambiental, a partir da Lei da Entropia, tendo como referência as discussões do economista e matemático Nicholas Georgescu-Roegen (G-R) (2012), Barbosa e Marques (2015, p. 1127) referem o seguinte:

G-R conclui que a matéria-energia absorvida pelo processo econômico ocorre num estado de baixa entropia e retorna num estado de alta entropia. 
Considerando que o calor não pode se reverter em matéria nos processos de produção e que nem toda a energia está disponível para ser utilizada [...] percebe-se que, com o passar dos tempos, nossos estoques energéticos e materiais se reduzem.

Para pensar a sustentabilidade ambiental, é fundamental garantir a diminuição dos fluxos de energia e matéria que perpassam o sistema econômico (VEIGA, 2010), embora, inexoravelmente, ocorram perdas irreversíveis na sua interconversão, por conta das leis termodinâmicas (MARQUES; MACHADO, 2014). Porquanto é necessário ao mesmo tempo que consideramos a irreversibilidade da degradação entrópica, nos afastemos " [...] do senso comum, por exemplo, sobre o uso parcimonioso ou da economia de recursos naturais - ainda que importantes - aceitar a ideia da finitude destes em nosso planeta" (BARBOSA; MARQUES, 2015, p. 1127-1128). Nesse sentido, é imperioso registrar também que devemos admitir a impossibilidade da ciência e da tecnologia de tudo resolver (BAZZO, 2014), não propalando mitos salvacionistas em relação a ambas (AULER, 2002).

É nesse contexto que apoiamos a ideia de difundir a articulação da Lei da Entropia (2 ${ }^{\underline{a}}$ Lei da Termodinâmica) com o conceito de sustentabilidade, com o escopo de problematizar e melhor compreender a dimensão ambiental que envolve o próprio conceito de sustentabilidade. Estamos certos de que isso contribuirá para uma postura mais crítica sobre o conceito e suas relações e demandas em processos formativos conduzido na perspectiva CTS, como, por exemplo, no caso sugerido por Barbosa e Marques (2015), ao discutirem um acidente agrícola no estado do Mato Grosso em um curso de formação de técnicos agrícolas.

Por outro lado, mesmo reforçando a importância desse vínculo entropia e (in)sustentabilidade, Melo (2006, p. 83-84) pondera o seguinte:

[...] somente o conceito de entropia é insuficiente para tratar a complexidade ambiental, em especial quando se considera seu componente social [...], pois no centro da dinâmica social [...] está o capital, que produz assimetrias desigualdades: ora, não há nenhum processo natural nisso, que poderia ser 'ocultado' se fundamentássemos a análise somente no prisma dos processos termodinâmicos. Faz-se, portanto imprescindível para nós que se estabeleça a inter-relação entre o princípio da entropia e a lógica de reprodução do capital. 
Assim há ainda que se considerar que

O modelo societário vivido pela humanidade enfrenta uma severa crise: crise de identidade cultural, crise do modelo de produção e circulação de bens, crise dos valores e princípios éticos que orientam os indivíduos em seus hábitos de consumo e descarte, crise da insuficiência de recursos naturais para sustentação destes hábitos, crise imposta pelo limite de crescimento populacional e econômico, derivada também da escassez de recursos naturais, enfim, crise do paradigma societário sustentado pelo modelo capitalista, em cuja racionalidade cabe ao ser humano o domínio da natureza e a escravização do próprio ser humano [...]. (BIGLIARDI; CRUZ, 2007, p. 41).

Dessa forma, depreendemos que, ao se discutir o tema (in)sustentabilidade, precisamos considerar suas múltiplas dimensões, sem ocultamentos da gravidade das múltiplas crises que vêm se estabelecendo na atual sociedade.

Para complexificar ainda mais o cenário e as expressões (terminológicas, inclusive) da crise, o termo sustentável vem frequentemente associado ao do termo desenvolvimento (Desenvolvimento Sustentável). Inserido em um campo de embate político e teórico, esse conceito abriga "[...] múltiplos discursos que ora se opõem, ora se complementam" (NASCIMENTO, 2012a, p. 51). Na confluência de discursos dos mais variados e conflitantes sobre o Desenvolvimento Sustentável, notadamente ao considerarmos sua alocação no contexto de um modelo produtivista-capitalista, é plausível que os conceitos, especialmente de sustentabilidade (ambiental), careçam de inteligibilidade. Mesmo porque, “[...] a ilusão de que o capitalismo possa se tornar ambientalmente 'sustentável' é a ideia mais extraviadora do pensamento político, social e econômico contemporâneo" (MARQUES, 2015, p. 471).

A abordagem dos contextos de (in)sustentabilidade que permeiam as questões socioambientais, em termos de sua evolução e compreensões disseminadas, exige um esforço teórico e prático apreciável, inclusive no campo educacional. O fato é que, sob a égide do Desenvolvimento Sustentável ou sob a prerrogativa da sustentabilidade, os processos de desenvolvimento postos pelo cenário capitalista têm levado ao agravamento das condições ambientais, comprometedora do prolongamento da vida no planeta (VEIGA, 2010). Mas, para muitos, principalmente para a maioria da população, isso não é algo facilmente compreensível. Eis a forte importância dos processos educativos em espaços formais e não formais. 
Portanto as discussões sobre sustentabilidade não podem escapar ao campo educacional, notadamente sob a perspectiva do enfoque CTS, posto que tal enfoque pressupõe tratamento crítico dos conteúdos de ensino na sua multiplicidade de referências. As abordagens das relações CTS, com o tema da sustentabilidade, precisam revelar as ausências de comprometimento com o ambiente natural ante os pressupostos que direcionam o desenvolvimento para a valorização da dimensão econômica em detrimento das demais dimensões do processo.

\section{E o amanhã?}

As previsões de um amanhã, compatível com a possibilidade de a espécie humana evitar sua própria extinção ou, pelo menos, retardá-la ao máximo (considerando os postulados termodinâmicos), apresentam-se crescentemente temerária. Vários eventos inter-relacionados configuram a crise ambiental (MARQUES, 2015). Nesse contexto de cenários insólitos, não podemos pensar em " $[\ldots]$ suspender o processo entrópico, mas sim de agir no sentido de que ele não seja ainda mais acelerado do que já o foi, por conta das atividades humanas" (VEIGA, 2010, p. 33). Por conseguinte, a “[...] busca pela sustentabilidade na dimensão ambiental compreende, entre outras medidas, o uso racional dos recursos naturais e a melhoria na eficiência técnica quanto às transformações materiais e ao uso de energia" (MARQUES et al., 2014, p. 80).

Se, por um lado, isso é correto, por outro, não podemos deixar de desconsiderar as demais dimensões, mesmo porque "[...] seria simplesmente ridículo pensar em sustentabilidade diante da suprema humilhação da própria espécie humana, da privação de suas liberdades e da estupidez de seus morticídios" (VEIGA, 2010, p. 37). A sustentabilidade como um novo valor (FREITAS, 2012; VEIGA, 2010), do pensar o amanhã e do agir no presente, demandará que esse valor seja infundido em todos os contextos societários. A educação constitui-se num desses contextos, capaz de favorecer a apreensão da realidade socioambiental, nas intricadas relações sociedade e natureza; ao mesmo tempo que contribui para a compreensão fundamentada sobre os elementos que desenham a atual crise ambiental. 


\section{REFERÊNCIAS}

AGÊNCIA BRASIL. Em visita histórica a Hiroshima, Obama lamenta mortes, mas não pede desculpas. 2016. Disponível em: <http://agenciabrasil.ebc.com.br/internacional/ noticia/2016-05/em-visita-historica-hiroshima-obama-lamenta-mortes-mas-nao-pede $>$. Acesso em: 08 ago. 2016.

AULER, D. Interações entre Ciência-Tecnologia-Sociedade no contexto da formação de professores de Ciências. 257 f. 2002. Tese (Doutorado em Educação) - Programa de Pós-Graduação em Educação, Universidade Federal de Santa Catarina, Florianópolis, 2002.

BARBOSA, L. C. A.; MARQUES, C. A. Sustentabilidade ambiental e postulados termodinâmicos à luz da obra de Nicholas Georgescu-Roegen. Revista Eletrônica em Gestão, Educação e Tecnologia Ambiental, Santa Maria, v. 19, n. 2, p. 1124-1132, 2015.

BAZZO, W. A. Ciência, tecnologia e sociedade e o contexto da educação tecnológica. Florianópolis: Ed. da UFSC, 2014.

BIGLIARDI, R. V.; CRUZ, G. R. O papel da educação ambiental frente à crise civilizatória atual. Ambiente \& Educação, Rio Grande, v. 12, p. 127-141, 2007.

BOFF, L. Sostenibilidad: ¿adjetivo o sustantivo? 2011. Disponível em: <http://www. serviciosokoinonia.org/boff/articulo.php?num=439>. Acesso em: 07 abr. 2016.

BOFF, L. Sustentabilidade: o que é, o que não é. Petrópolis: Vozes, 2012.

CARSON, R. Primavera silenciosa. São Paulo: Gaia, 2010.

CAVALCANTI, C. Meio ambiente, Celso Furtado e o desenvolvimento como falácia. Ambiente \& Sociedade, v. 5, n. 2, p. 73-84, 2002.

CAVALCANTI, C. Sustentabilidade: mantra ou escolha moral? Uma abordagem ecológico-econômica. Estudos Avançados, São Paulo, v. 26, n. 74, p. 35-50, 2012.

CECHIN, A. A natureza como limite da economia. São Paulo: SENAC; EDUSP, 2010.

COMISSÃO MUNDIAL SOBRE O MEIO AMBIENTE E DESENVOLVIMENTO. Nosso futuro comum. Rio de Janeiro: FGV, 1991.

CORTEZ, J. O legado de Madame Curie: uma abordagem CTS para o ensino da radioatividade. 66 f. 2014. Dissertação (Mestrado em Ensino de Física) - Programa de Pós-Graduação em Ensino de Física, Universidade Federal do Rio Grande do Sul, Porto Alegre. 2014.

DARWIN, E. Temple of nature; or, origin of society. A poem. 1804. Disponível em: < http://darwin-online.org.uk/converted/pdf/1804_Temple_A937.pdf $>$. Acesso em: 13 out. 2016.

DARWIN, E. The loves of plants and animals: romantic science and the pleasures of nature. 1794. Disponível em: <https://www.rc.umd.edu>. Acesso em: 13 out. 2016. 
ESTEBAN, M. S. Pesquisa qualitativa em educação: fundamentos e tradição. Porto Alegre: Artmed, 2010.

FAUSTINO, M.; AMADOR, F. O conceito de "sustentabilidade": migração e mudanças de significados no âmbito educativo. Indagatio Didactica, Aveiro, Portugal, v. 8, n. 1, p. 2021-2033, 2016.

FONSECA NETO, S. N.; FREITAS, N. M. S.; FREITAS, N. M. S. Uma carta para o futuro: constructos sobre (in)sustentabilidade. Ciência e Natura, Santa Maria, v. 39, n. 1, p. 133-141, 2017.

GEORGESCU-ROEGEN, N. O decrescimento: entropia, ecologia, economia. In: GRINEVALD, J.; RENS, I. (Org.). ISAAC, M. J. P. (Trad.). São Paulo: SENAC, 2012.

GUERRA, A. F. S.; FIGUEIREDO, M. L. Ambientalização curricular na educação superior: desafios e perspectivas. Educar em Revista, Curitiba, edição especial, n. 3, p. 109-126, 2014.

LAURIE, R. et al. Contributions of Education for Sustainable Development (ESD) to quality education: a synthesis of research. Journal of Education for Sustainable Development, USA, v. 10, n. 2, p. 226-242, 2016.

LAYRARGUES, P. P. O cinismo da reciclagem: o significado ideológico da reciclagem da lata de alumínio e suas implicações para a educação ambiental. In: LOUREIRO, C. F. B; LAYRARGUES, P. P.; CASTRO, R. S. Educação ambiental: repensando o espaço da cidadania (Orgs.). São Paulo: Cortez, 2002. p. 179-220.

LEFF, E. A aposta pela vida: imaginação sociológica e imaginários sociais nos territórios ambientais do Sul. Petrópolis: Vozes, 2016.

LYRA, D. G. Os três momentos pedagógicos no ensino de ciências na educação de jovens e adultos da rede pública de Goiânia, Goiás: o caso da dengue. 2013. 117 f. Dissertação (Mestrado em Educação em Ciências e Matemática) - Programa de Pós-Graduação em Educação em Ciências e Matemática, Universidade Federal de Goiás. 2013.

MARQUES, C. A.; MACHADO, A. S. C. Environmental Sustainability: implications and limitations to Green Chemistry. Fundations of Chemistry, USA, v. 16, p. 125-147, 2014.

MARQUES, C. A. et al. Compreensões de pesquisadores químicos sobre sustentabilidade ambiental. Revista Brasileira de Ensino de Química, Campinas, SP: Editora Átomo, v. 9, n. 2, p. 79-92, 2014.

MARQUES, L. Capitalismo e colapso ambiental. Campinas, SP: Editora da Unicamp, 2015.

MEADOWS, D. H. et al. Limites do crescimento: um relatório para o projeto do Clube de Roma sobre o dilema da humanidade. São Paulo: Editora Perspectiva, 1973.

MELO, M. M. Capitalismo versus sustentabilidade: o desafio de uma nova ética ambiental. Florianópolis: Editora da UFSC, 2006. 
MUIR, J. John Muir's Studies in the Sierra, 1898. Disponível em: < https://www.skoob. com.br/autor/12203-john-muir>. Acesso em: 13 out. 2016.

NASCIMENTO, E. P. Sustentabilidade: o campo de disputa de nosso futuro civilizacional. In: LÉNA, P.; NASCIMENTO, E. P. Enfrentando os limites do crescimento: sustentabilidade, decrescimento e prosperidade. Rio de janeiro: Garamond, 2012a. p. 415-434.

NASCIMENTO, E. P. Trajetória da sustentabilidade: do ambiental ao social, do social ao econômico. Estudos Avançados, São Paulo, v. 26, n.74, p. 51-64, 2012b.

NINIS, A. B.; BILIBIO, M. A. Homo sapiens, Homo demens e Homo degradandis: a psiquê humana e a crise ambiental. Psicologia \& Sociedade, Belo Horizonte, v. 24, n. 1, p. 46-55, 2012.

OLIVEIRA, M. M. Como fazer pesquisa qualitativa. 6. ed. Petrópolis: Vozes, 2014.

OLIVEIRA, R. D. V. L. de; QUEIROZ, G. R. P. C. (Org.). Olhares sobre a (in)diferença: formar-se professor de ciências a partir de uma perspectiva de Educação em Direitos Humanos. São Paulo: Livraria da Física, 2015.

OLIVEIRA, L. D. Os "limites do crescimento" 40 anos depois: das "profecias do apocalipse ambiental" ao "futuro comum ecologicamente sustentável”. Revista Continentes, Rio de Janeiro, n. 1, p. 72-96, 2012.

PIMENTA JÚNIOR, F. G. Gestão e planejamento na prevenção e no controle da dengue. VALLE, D.; PIMENTA, D. N.; CUNHA, R. V. (Org.). Dengue: teorias e práticas. Rio de Janeiro: Fiocruz, 2015. p. 381-406.

PINHEIRO, N. A. M.; SILVEIRA, R. M. C. F.; BAZZO, W. A. O contexto científico-tecnológico e social acerca de uma abordagem crítico-reflexiva: perspectiva e enfoque. Revista Iberoamericana de Educación, España, v. 49, n. 1, p. 1-14, 2009.

POLITO, A. G. M. Moderno Dicionário da Língua Portuguesa. São Paulo: Melhoramentos, 2004.

PORTO-GONÇALVES, C. W. A globalização da natureza e a natureza da globalização. Rio de Janeiro: Civilização Brasileira, 2012.

REST, J. El laberinto del universo: Borges y el pensamento nominalista. 2009. Disponível em: $<$ https//pt.scribd.com/document/66052325/Rest-Jaime-El-Laberinto-Del-Universo-Borges-y-El-to-a.>. Acesso em: 13 set. 2016.

SILVA, M. A. Vivenciar para apreender: o meio ambiente como contexto para o ensino de polímeros. 88 f. 2014. Dissertação (Mestrado Profissional em Química) - Programa de Pós-Graduação em Química, Universidade Federal de São Carlos. São Carlos. 2014.

SILVEIRA, R. M. C. F.; BAZZO, W. A. Ciência, tecnologia e suas relações sociais: a percepção de geradores de tecnologia e suas implicações na educação tecnológica. Ciência \& Educação, Bauru, v. 15, n. 3, p. 681-694, 2009. 
THOREAU, H. D. Walden. Tradução de Denise Bottmann. Porto Alegre: L\&PM, 2014. TRIGUEIRO, A. Não há sustentabilidade sem paz. 2012. Disponível em: <http://boletimmeioambiente.blogspot.com.br/2012/05/nao-ha-sustentabilidade-sem-paz.html>. Acesso em: 25 jul. 2016.

VACARRO, S. G. Jorge Luis Borges: um crítico da linguagem. 2013. 350 f. Tese (Doutorado em Literatura) - Programa de Pós-Graduação em Literatura, Universidade Federal de Santa Catarina. Florianópolis. 2013.

VASCONCELOS, E. R.; FREITAS, N. M. S. O paradigma da sustentabilidade e a abordagem CTS: mediações para o ensino de ciências. Amazônia. Revista de Educação em Ciências e Matemáticas, Belém, v. 9, n. 17, p. 89-108, jul. 2012/dez. 2012.

VEIGA, J. E. Desenvolvimento sustentável: o desafio do século XXI. Rio de Janeiro: Garamond, 2005.

VEIGA, J. E. Desenvolvimento sustentável: que bicho é esse? Campinas: Autores Associados, 2008.

VEIGA, J. E. Sustentabilidade: a legitimação de um novo valor. São Paulo: SENAC, 2010.

VILCHES, A.; GIL-PÉREZ, D. Ciencia de la Sostenibilidad: ¿Una nueva disciplina o un nuevo enfoque para todas las disciplinas? Revista Ibero-americana de Educação, España, v. 69, n. 1, p. 39-60, 2015.

ZANETI, I. C. B.; SÁ, L. M.; ALMEIDA, V. G. Insustentabilidade e produção de resíduos: a face oculta do sistema do capital. Sociedade e Estado, Brasília, v. 24, n. 1, p. 173-192, 2009.

Texto recebido em 29 de novembro de 2016. Texto aprovado em 09 de fevereiro de 2017. 
